Revista ch ANPOLL, "1" 5, p. 77-105, jul./de:.., 1998

\title{
DE SONS DE POETAS \\ OU \\ ESTUDANDO FONOLOGIA ATRAVESS DA POESIA
}

\author{
Gladis Massini-Cagliani" \\ Iuiz Carlos Cagliari*
}

\begin{abstract}
RESUMO: Neste trabatho, pretende-se demonsturar que a consideraģüo da poesiat como objelo de estudes pode combribuir na descriçūo gramatical, em especial de elementos fonolígricos - sobretudo prosiódicos. Em relaçõo ao estudo desseses fenô-

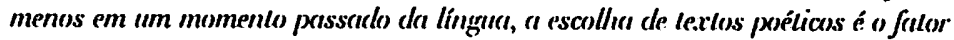

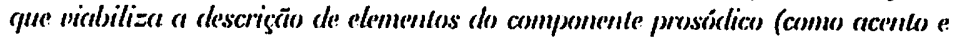

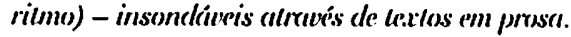

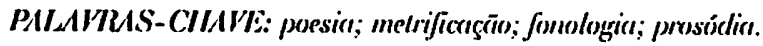

\section{INTRODUÇĀO}

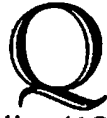

uando Mattoso Câmara, com o scu Contribuição à Esstilística Portuguesa, cm 1953, tentou cstabelecer as bases da Estilistica de Bally (1951) dentro da linguística brasilcira, sua proposta, cm um certo sentido, cra ampliar o conceito de Cramática. Considerando as três funçôcs da linguagem propostas por Bühler (1934) - a saber, manifestação anímica, atuação social (apelo) c representação mental -, Ciâmara Jr: (1953: 23), afirma que "o que o conceito saussureano de língua afasta decisivamente de si, se inclui, ao contrário, naruele conceito de estilo". Isto

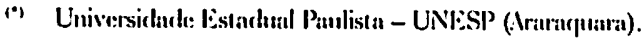

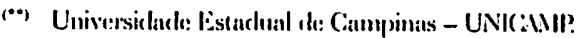




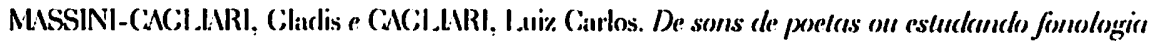
retruerses cla poessitu.

porque a língua, no scu conceito saussurcano, se deduz apenas da função representativa, comprecndendo csscncialmente a sua estrutura, c cstando, deste modo, na própria essência da linguagem, mas deixando de lời fenômenos cspecíficos da manifestação anímica c do apclo, cmbora cssàs funções sc desdobrem sobre a pauta do sistcma intelectivo das representações simbólicas.

A partir desta constatação, a cxcmplo de Bally, Mattoso Câmara propõc uma ampliação da Cramática nos scguintes termos: cxistiriam duas manciras de se conceber a Gramática de uma língua, mesmo sem deixar de lado uma concepção estruturalista de sistema - uma lato c outra stricto sensu. Uma Cramática stricto sensu cnglobaria os diversos níveis de descrição lingüística tradicionais, da mancira como propostos pcla tcoria cstruturalista, ou scja, os nívcis fonológico, morfológico c sintático. Já na Cramática lato sensu cstariam incluídos todos os fenômenos de cstilo, cuualçucr çue scja a definição que csta palavia receba dentro da I inguiística.

Abrc-sc, desta forma, uma porta para fazcr de todas as linguagens que scjam, de certo modo, "individuais", objeto lcgítimo da I ingüística. Dentre cstas, a pocsia, manifestação anímica e de estilo individual por cxceIência.

Não ć à toa, pois, que, na mesma ćpoca cm que toda cssa discussão a respeito de cstilo se descnvolvia, Jakobson (1960), cm scu famoso trabalho sobre as funções da linguagem, batiza de poética a funçĩo da linguagem que focaliza a própria mensagem. Scgundo Martins (1989: 13), aproximando a teoria de Jakobson da de Bally, "para Jakobson a Estilística, ou Poética, se concentra na relação da funçãos poética com as demais funç̄̃es".

No cntanto, cmbora a influĉncia dos cstudos estilísticos tenha sido decisiva para a consideração da pocsia como objeto legítimo da Ijingüística, é necessário salientar que, mesmo cm uma concepção de l.jingüística stricto sensu, as manifestaçōes poćticas devem ter um lugar de igual destaque em relação aos outros textos dignos de figurar em corpora de estudo. lim alguns casos, devem até mesmo ser privilegiados. É o que acontece 
quando, dentro da Fonologia, se quer estudar fenômenos prosódicos de um período passado da língua, quando não havia, ainda, tecnologia suficientc para gravar a fala. Mas também em relação ao momento atual da língua, muitos fatores podem ser cstudados a partir da cstrutura poćtica de um texto, especialmente se este for metrificado.

Como diz Allen (1973: 103):

"... metrical phenomena cannot be ignored, since, especially in the crise of 'decal' languages, the relationship between proty and ordinary language may provide clues to the prossodic pallerning of the laller; and in any case verse form is a form of the language, albeil specialized in funclion, and enlilled to some consideration as such."

Dentre os fenômenos fonológicos que muito podem se bencficiar; na sua descrição, da consideração de textos poćticos para a construção da Cramática de uma língua, estão o acento c o ritmo. Para Abercrombic (1967: 98), o ritmo da fala corrente ć o fundamento do verso; portanto, fala e poesia não se distinguem tipologicamentc quanto ao ritmo (Abercrombic, 1965: 18). Para ele, a única difcrença entre o ritmo da fala e da poesia ć que, na poesia, ele se encontra organizado de maneira a produzir (c a fazer com que o ouvinte/leitor perceba) padrōes recorrentes. Como Abcrcrombic trabalha com a noção de ritmo silábico c ritmo acentual, estes padröes recorrentes variam de acordo com o tipo de língua. Desta mancira, os padrões recorrentes $\mathrm{cm}$ um pocma escrito $\mathrm{cm}$ uma língua de ritmo silábico (sílabas) são obviamente diferentes dos padrões recorrentes $\mathrm{cm}$ outro, cscrito $\mathrm{cm}$ uma língua de ritmo acentual (pés), mas o quc tais poemas têm em comum são padrões recorrentes de ritmo, que causam a sensação de ritmo poético.'

(1) Seguindo a orientação de Abercrontbic, Cagliari (1984) faz uma auńlise de diversos poemas do portuguếs. Partindo também dessa distinçāo entre ritmo sillábico e ritmo acentuul, Lechiste (1985, 199)) procura analisar instrumentalmente através do sinal acústico textos poćticos lidos com vo\% alta, com busca, no texto de 1985, de diferenças rítmicas entre textos pośticos e em prosa. No texto de 1990, ela 


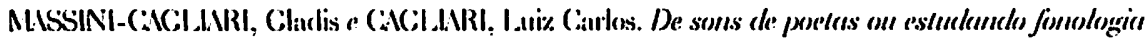
alsureis cla porssia.

lEntretanto, para Verluyten (1982: 36-37), a prosódia de uma língua não pode ser estudada somente no nível da sua realização fonćtica, como o fazem Abercrombic c Cagliari (1984), mas a descriçāo deve atingir um ccrto nívcl de abstração fonológica:

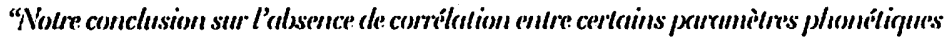

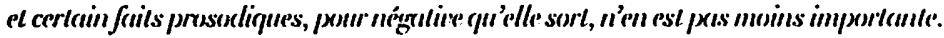

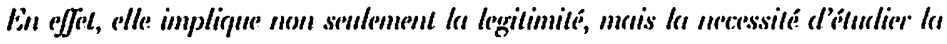

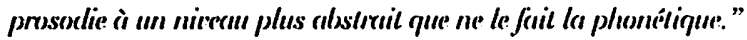

Estudando os versos alexandrinos franceses, Verluyten (1982: 257) afirma que as categorias métricas são versões estilizadas de certas categorias prosódicas (definidas conforme os preccitos da fonologia prosódica). Desta mancira, o "verso" correspondc ao "enunciado", o "pé métrico" à "palavra prosódica", c assim por diante. $\mathrm{O}$ autor chega a generalizar; dizendo que toda catcgoria métrica tem seu equivalente $\mathrm{cm}$ uma categoria prosódica da língua (mas não necessariamente vice-versa). Mas, embora cada categoria métrica tenha sua correspondente prosódlica, class não coincidem, isto é, clas não sño necessariamente co-extensivas (caso contrário, a distinção entre métrica c prosódlia não faria sentido). Desta mancirá, o equivalente prosódico do verso é o enunciado, mas é evidente que os dois não coincidem sempre na linguagem versificada.

No décimo capítulo ("Prosodic domains and the meter of the ('ommedia") do livro de 1986 de Ncspor \& Vogel, também são fornecidas cvidências a favor da corrclação entre catcgorias prosódicas c métricas, obtidas a partir da análise que as autoras fazem das estruturas métrica c prosódica de versos da Divina Coméclia, de Dante.

Também I layes (1989) mostra a relevância da consideração da hicrarcquia prosódica no estudo do ritmo poćtico, ao analisar os metros trocai-

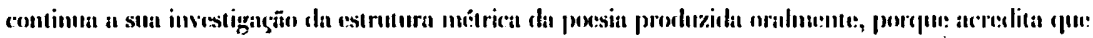

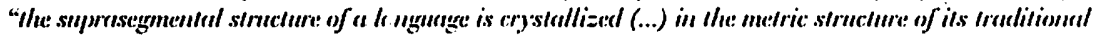
poctry:" 
Revistu de INPPOLL, 11" 5, p. 77-105, jul./de\%,., 1998

cos de "/liawatha", de longfellow. Para cle (p. 255), três são os fatores que provam esta relevância: a consideração da hicrarquia prosódlica permitc que um grande número de regras métricas (i.c., de versificaçāo) scja formulado de mancira mais simples e mais acurada; uma regra particular, a "Bounding Theory" cm "Iliawatha", é suficientemente generalizante para servir como base de diagnóstico de parentetizaçōes que correspondem às da hicrarcquia prosódica; a tcoria prosódica desenvolvida por I layes (1989), a partir de trabalhos anteriores de Selkirk c Nespor \& Vogel, fornece a base para uma tipologia restritiva, porém empiricamente adequada, das regras de versificação em inglês.

Alguns outros trabalhos podem ser citados, por também acreditarem que é $\mathrm{cm}$ um nível mais abstrato do que o da fonćtica (ou scja, no nível fonológico) que podem ser inferidas as estruturas que regulam os versos compostos $\mathrm{cm}$ uma determinada língua. Eintre cles, figuram os de I lalle \& Kcyser (1971), Maling (1973), Youmans (1989), Prince (1989), I lalle (1989) c Kiparsky (1989).

No cstudo de I lalle \&. Keyser (1971), os autores fornecem um panorama da evolução dla acentuação do inglês, cstudando-a atıavés de textos poéticos. A primcira parte do livro fornece uma análise do acento do inglês amcricano atual ("moderno", como preferem chamá-lo), com base no modelo da fonologia gerativa de (homsky \&. Ilalle (1968). Na segunda parte, apresentam uma análise do acento do inglês em três períodos históricos: Old English, Late Middle English c Early Modern English. Apenas para a última fase da sua análise dispumham de dicionários de rimas e observações de tratadistas sobre a posição do acento nas palavras da ćpoca. Já para as duas primciras fases, foi preciso escolher um corpus poćtico e procurar; nos limites dos próprios versos, indicações da localização do(s) acento(s). A claboração de um estudo de tal vulto, como este de l lalle \&. Keyser; só é possível quando se assume que o acento é governado por "ıcgras abstratas", que podem ser inferidas a partir da estrutura metrilicada dos versos (I lalle \&. Keyser; 1971: xi). I lá no livro, ainda, uma terceira 


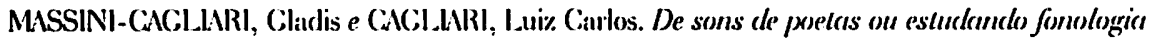
atruvés cla poesia.

parte, em que é desenvolvida a tcoria de metrificação dos autores. Propõcm que versificar é introduzir uma seçüência de palavras em um único padrão abstrato, cstabclecendo uma correspondência cntre os clementos constitutivos deste padrão c propricdades fonćticas (ou fonológicas) específicas da scqüência de palavras cm questão - Halle \&. Kcyscr (1971: 140).

Maling (1973) propõc uma nova análisc do sistema da pocsia árabe clássica, sugcrindo que uma cspécic de "gramática métrica" pode dar conta daquele sistema de metrificação. Desta forma, regras de base geram um único padrão métrico abstrato (c correspondente estrutura arbórca), de que são derivados todos os outros padrōes métricos. A partir daí, vários tipos de transformações (suprcssão, cópia c substituição) gcram outros padrões abstratos que correspondem aos subgrupos de metros tradicionalmente chamados de "círculos" (base da poesia árabe clássica).

Youmans (1989), na Introdıção da colctânca de artigos de cque fazcm partc Prince (1989), Hallc (1989), Kiparsky (1989) c Hayes (1989), aprovcita para apresentar as divergências c convergências entre os cstudos lingüísticos c litcrários do ritmo poćtico c defender uma visão "gcrativista" destes padrōes. Para cle, todos os que procuram estabelecer condiçōes explícitas de permissibilidade da ocorrência de versos, ao invés de apenas fazcr uma lista dos tipos possívcis, são, a scu modo, "gcrativistas" - até mesmo literatos tradicionalistas.

Prince (1989) vai mais longc. Formula uma tcoria que define que tipos de pés são permitidos $\mathrm{cm}$ vcrsos metrificados, testando-a através de cvidências cmpíricas fornecidas pela pocsia quantitativa grega c árabe clássica. Uma de suas muitas conclusões é que tanto o pé como o metron (uma unidade métrica hicrarcfuicamente supcrior ao pé) são cssenciais para a descrição acurada dos padrões métricos encontrados. Halle (1989) faz um "Adendo" à teoria de Prince, discutindo a introdução dos metros árabes na pocsia hebraica, em meados do século $X$.

Kiparsky (1989) analisa o "sprung rhythm" de Hopkins, tido como um ritmo "indecifravelmentc idiossincrático" (Youmans, 1989: 12) por 
estudos anteriores. Argumenta que as escansões dos pocmas de Hopkins fazem sentido se os accntos forcm interpretados como posições marcadas como fortes $\mathrm{cm}$ nívcis prosódicos hicrarquicamente supcriores ao das palavıas, ao invés de sílabas accntuadas no nível das palavias. \&, assim, constrói mais um engenhoso argumento favorável ao tratamento "mais abstrato" do ritmo poćtico.

Como mostram todos os trabalhos citados acima, a cscolha de textos poéticos para se estudar fenômenos prosódicos (c, em especial, o acento c o ritmo) de uma língua, inclusive e principalmente cm scus estágios passados, já sc provou adequada c cficaz, sobretudo quando se toma a descrição cm um nível "mais abstrato".

Assim, dentro deste contexto, pretende-se, neste traballo, fornecer alguns cxemplos de como a consideração da poesia enquanto objeto de cstudo pode contribuir na descrição gramatical, sobretudo de elementos fonológicos - com especial ênfase cm fenômenos prosódicos.

\section{PROSÓDIA E POESIA}

Passaremos, a seguir; a fazer alguns comentários específicos a respeito da relação entre métrica c ritmo lingüístico.

A tradição da análise poćtica tem mostrado que a poesia pode revelar a duração das sílabas, a localização de acentos c pausas (cesturas) e um valor melódico/rítmico de natureza acústica. Com basc na obscrvação desses fatos, descnvolveram-se, dentro dessa tradição de análise poética, vários "mćtodos" de descrição, que passam a ser considerados.

O método quantitativo (Manucl Cavalcanti Proença, 1955) atribui durações relativas (longas c breves) às sílabas dos versos - cxemplo (1). As línguas que apresentam oposição fonológica cntre sílabas longas c breves, como o L Latim c o Crego, usam a duração silábica para constituir os metros, 


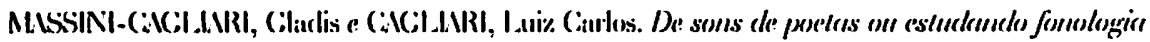
alrourés da possiot.

com os quais formam os versos - cxemplo (2). Como se vê cm (1) e (2), os versos de qualquer tipo de língua podem ser interpretarlos como uma sucessão de sílabas longas c breves (cventualmente cxtra-longas, como as sílabas tônicas rcforçadas pcla cntoação, ou cxtra-breves - Caggliari, 1982).

(1) Nāŏ chō / rěs que ă vĩda ě lū / tă rĕnhīida

(2) Haēc făcù / ēs 'liō /

O método acentual marca apenas as sílabas dos versos como sendo acentuadas ou átonas, como na tradição poćtica inglesa. O mesmo aplicàse a qualquer verso de qualquer língua (3), uma vez que todas as línguas têm uma procminência identificável como acento (mesmo no casso de línguas tonais).

$$
\text { - } 0 \text { - - - o- - - - } \quad-\text { = átona }
$$

(3) As armas c os varốcs assinalados $0=$ tônica

O método musical parte do princípio que as línguas tendem a ter um certo compasso musical. Assim, a língua Portugucsa tende a se bascar em um compasso do tipo 2/4 (cf. Cavalcanti Proença, 1955) - cxemplo (4):

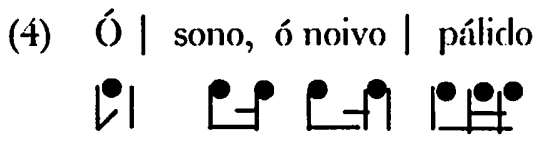

Outros métodos, como os estatísticos, procuram tirar da estrutura rígida que os versos metrificados devem ter em princípio regularidades a respeito do ritmo, andamento, e até da qualidade fonćtica de elementos (Croot, 1968: 545). O Método Acústico foi proposto por Jakobson (apud 
Revister ctu ANPOLL, in" 5, p. 77-105, jul./de\%, 1998

(root, 1968), tentando reconhecer nos elementos acústicos da fala de pocmas o que traz a sensação do ritmo c andamento poético. Infelizmente, ainda há poucos estudos claborados a partir desse arcabouço tcórico.?

Ciomo já demonstrado cm outro estudo (Cagliari, 1984: 76-96), essas abordagens revelam apenas aspectos parciais do sistema rítmico e métrico das línguas. Porém, individualmente, ajudam a mostrar fatos fonéticos c fonológicos sob detcrminado ponto de vista.

Pocsias não metrificadas (pelas regras tradicionais) podem revelar; pela disposição dos versos, a definição de grupos tonais - cada verso sendo um deles. Isto revela claramente o andamento e a concatenação, além do comportamento de padrões entoacionais, em termos de clementos prosódicos da língra - exemplo (5).

(5) No meio da noite despertei

Não ouvi mais vozes nem risos

Apcnas balões

Passavam crrantes

Silenciosamente

Apenas de ve\% cm quando

O ruíclo de um bonde

Cortava o silêncio

Como um túncl.

No cxemplo acima, tirado de Manuel Bandeira, o autor poderia ter disposto os versos de outra mancira - mas isso alteravia a estruturce dos grupos tonais, levando a resultados prosódicos indescjados pelo autor: Considerações dessa natureza mostram também como se pode e como não se

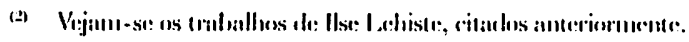




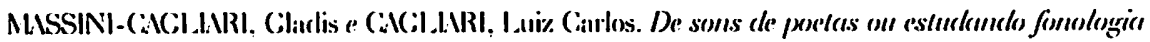
retramés cla porsia.

pode "segmentar" um cnunciado cm grupos tonais. Nem todo verso branco corresponde a um grupo tonal, mas, em alguns poemas, isso é imperativo, pois, um dos "segredos" de fazer pocsia e de senti-la cstá justamente no fato de se reconhecer tal padrão prosódico nos versos.

Outro exemplo pode ser visto nos seguintes versos de Cassiano Ricardo, que pretendem imprimir a estrutura de um toque binário de tambor; através da recorrência de duas batidas acentuais (dois acentos) por verso:

(6) Lintão o vento

I Lá dentro da serra

Onde apcnas havia

$\mathrm{O}$ barullo insensato

Das coisas sem nome

Começou a bater

A batcer rataplä

No tambor da manhã

Outros clementos poćticos também contribuem para a identilicaçã̃o de padrōes prosódicos, como o ritmo c o andamento. Éntre cles, a estrutura de estrofes em certos tipos de pocmas marcam claramente esses padrōes, como os pocmas paralclísticos do Português Arcaico, pocmas com refião, antífona, ctc.

As rimas, por outro lado, constitucm um dos materiais mais preciosos para se tirar da cscrita, através da poesia, clementos fonćticos c fonológicos. Pela comparação entre escrita c resultado de rima em poesias, pode-se até mesmo chegar a conclusões bastante seguras a respeito da pronúncia do pocta c, consecjüientemente, de scu dialeto c de sua época. Por exemplo, um pocma cm que há rimas do tipo touro - morro ou bandeira - pêra revelam que os ditongos/ow/c/cj/ apresentam uma variante monotongada $|\mathrm{o}| \mathrm{e}|\mathrm{e}|$. 


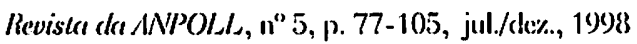

Um padrão de final de verso - que faz rima apenas com vogais - c que apresente álibi-cálice - cale-se mostra a ocorrência fonćtica do padrão |a i. - i). Infelizmentc, como a língua Portuguesa apresenta muitos processos fonológicos do tipo variação cm distribuição complementar; fica impossível, somentc através da cscrita, mesmo de poesias metrificadas, identificar a pronúncia. Por cxemplo, ocorrc o foncma $\left|\int\right| \mathrm{cm}$ início de sílabas (posição de onsct): xícara, chapéu, ctc. Em alguns dialctos, como o carioca, ocorre também no final de sílabas (posição de coda): paz, mas, ctc. Como não se cscreve com dígrafos cssa pronúncia da coda, mas apenas com as letras $\%$ c S, nunca se poderá ter certcza sobrc sua realização fonćtica, a não scr que sc tenha uma descrição bascada na observação da fala de indivíduos. Apenas através da escrita (por cxemplo, de textos medievais) é, praticamente, impossível detcctar cssc tipo de variação.

As pocsias - metrificadas ou não - à scmclhança da prosa, apresentam clementos de pontuação c demais marcas que servem para sinalizar realizações prosódicas. Vírgulas c pontos costumam delimitar grupos tonais; pontos de cxclamação, de interrogação, reticências, ctc., costumam indicar padrōes cntoacionais básicos (tons primários) e atć mesmo certas atitudes do falante responsáveis por padrões entoacionais sccundários (tons sccundários) (Cagliari, 1982). 3 É muito comum reconhecer no uso de vírgulas a ocorrência de tom 3 (suspensivo), no uso de ponto final, a ocorrência de tom 1 (asscrçāo), c, no uso do ponto de interrogação, a ocorrĉncia de tom 2 (intcrrogativo) - sc não houver palavıra "intcrrogativa" na frasc (tipo: quem, onde, o que, etc.). Na verdade, cm relação ao sistema de pontuação, tudo o que se pode afirmar da prosa, pode-sc atribuir à pocsia, cmbora o contrário não scja verdade, uma vez que algumas considerações a respeito de certos fatos fonćticos c fonológicos somente podem ser feitas dentro da cstrutura poćtica, sc sc está apenas diante da cscrita c não da fala propriamente dita (Cagliari, 1989).

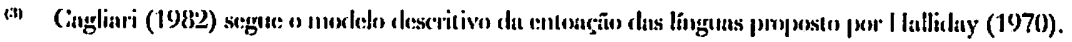




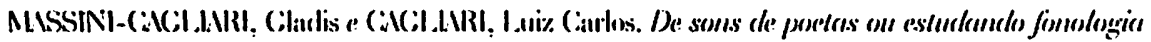
ralrumes che porsicts.

Um fato interessante e pouco pesquisado com relação à mancià como at escrita pode revelar aspectos da fala reside no estudo do signilicado de palavras que, por sua natureza semântica, remetem a fitos de fiala. Por cxemplo: dizer suavemente, dizer pensativamente, esbraurjar, sussirrrar; perguntar; gritar; suplicar; dizer chorando, etc. sĩo verdadeiras rlescriçōes prosódicas dentro do próprio texto. Algumas apresentam implicaçōos claras: quem suplice não vai usar uma velocidade rápida para dizer o que quer e sim vai procurar destacar mais as palavras, silabando-as (Caygliari, 1992). O modo "tradicional" de ler pocsia não costuma incorporar uma realização prosódica marcada cxplicitamente na cscrita, acabando cm um nivelamento prosódico muito diferente do que se encontra na lala real clas pessoas. Mesmo certos poetas, Iendo seus poemas, acibam por interpretílos dessa mancira. liste é um fruto da escolaridade, que obrigga os alunos a lerem assim. Por outro lado, interpretaçōes artísticass, leiturass rliamníticass, têm mostrado que os artistas de palco interpretam ats poesias de mancina muito mais próxima do modo como as pessoas falam. Nesses casos, a riqueza prosódica reaparece em seu esplendor:

Nos exemplos apresentados a seguil; notia-se a descriçion de um certo tipo de qualielade de vo\% ("dizer com mágoa", "palavras cansardiss", "voz triste e piedosa", "com um tom de voz horrendo e grosso", "voz pesada c amara") e da fala propriamente dita - o que se disse com qual qualidade de voz. Descrições desse tipo abrangem o conteúdo semântico (ou atitudes do falante) que a (Cramática de uma língua associa a dificrentes qualidarles de voz. Ėmbora precariamente, com esses elementos jí é possivel reconstituir parte do sistema prosódico que relaciona contoaşiio, ritmo e atitude dos falantes.

(7) "Alı! Diogo cruc!!" disse com miiguia, E, sem mais vista ser; sorveu-se n'ígual...

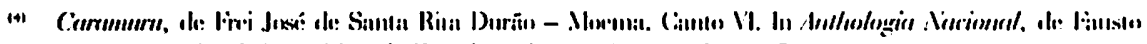

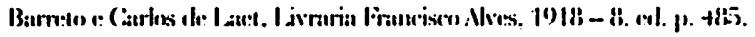


(8) Um coitado de um pastor;

Thiste, mal aventurado,

Vencido de grande dor;

Ao derredor de seu gado,

Se queixava do amor:

Com palavras cansadas,

Sem descanso, c sem cansar;

A quantos via passall;

Com vozes desesperarlas

Os faria csperar:"

(9) Ela, com tristes e piedosas vozes, Saídas só da mágoa e sautudade

Pera o avô crucl assi dizia:

"Se já nas brutas feras, cuja mente ..."

(10) C'um tom de voz nos fala, horrendo e grosso,

Que pareccu sair do mar profundo:

Arrepiam-se as carnes e o calselo

A mi c a todos, só de ouvi-lo e vê-lo.

li disse: "Ó gente ousada mais que quantas

No mundo comcteram grandes cousas ...?

A boca e os ollios negros retorcendo

Ei dando um espantoso e grande brado

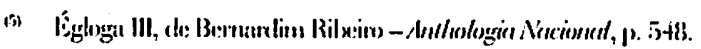

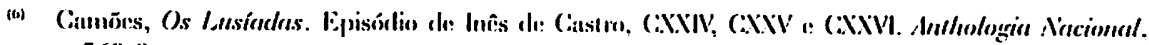
1). 568-9.

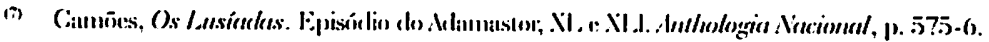




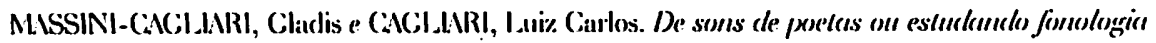
alorwés da poessia.

Mc respondeu com voz pesada c amara,

Como cuem da pergunta lhe pesara:

Eu sou aquele oculto c grande cabo..."

Uma outra fontc importante para os estudos de Fonologia, baseitdos $\mathrm{cm}$ análises de pocsias, sobretudo antigas, para as quais não $\mathrm{se} \mathrm{tem}$ registro oral gravado da ćpoca de scus autores, é o que se encontra cm gramáticas $\mathrm{c} \mathrm{cm}$ tratados de metrificação da época dos poemas. Os comentários dos gramáticos $\mathrm{e}$ dos teóricos da literatura revelam fatos que a ortografia c a escrita, $\mathrm{cm}$ geral, cscondem. Por exemplo, quem garante que todo A do latim tinha o som de $|\mathrm{a}| \mathrm{e}$ nunca de um chuá ou de uma vogal postcrior fechada não-arredondada, como se encontra no Português Europeu c no Japonĉs (quando sc observam as transliteraçōes do sistema de escrita japonês para o alfabcto latino)? A prosódia latina, porém, logo perccbeu que havia pelo menos um |ā| e um |ă| e que esta diferença crà crucial para a formação dos metros poćticos. Atualmente, sabemos que o sistema latino de vogais funcionava dessa mancira, não porque identificamos a diferença na escrita, mas porque os gramáticos descreveram o fenômeno com detalhes, inclusive dando regras.

No entanto, a confiança em informaçốcs collidas $\mathrm{cm}$ tratados de gramática ou prosódia não pode ser total, pois, infelizmente, nota-sc que é muito comum um gramático ou teórico da litcratura copiar outro, mesmo quando os dados da fonte referiam-se a línguas diferentes. Isto tem levado a tradição cscolar a sérios equívocos. Para um língua, contar sílabas pode ser uma estratégia métrica importante, mas, para outra, será o acento o principal fator rítmico. Com uma única e mesma abordagem teórica de metrificação para línguas diferentes, o resultado pode ser estranho, quando não crrado, ao ponto absurdo de o estudioso forçar os

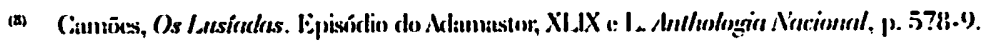


dados para sc adaptarem aos modelos tcóricos, desfigurando a língua c enchendo os tratados de exceções, para justificar o que os poctas mais famosos fizcram."

Uma posição diferentc é utilizar um modelo teórico, adaptando-o aos fatos reais da língua numa determinada ćpoca. Um bom cxemplo disto é a mancira como o gramático Jerônimo Soares Barbosa (1822) descreve o ritmo da Língua Portuguesa. Sua contribuição é algo muito precioso para se entender alguns fatos prosódicos da Língua Portuguesa de scu tcmpo. O fato de clc usar um modelo tcórico bascado no da gramática latina, na verdade, acaba se reduzindo apenas a uns tantos "rótulos", uma ver que os excmplos que dá e comenta revelam uma realidade prosódica muito diferente da encontrada na gramática latina. ${ }^{10}$

No caso da Língua Portuguesa, há ainda outros gramáticos c tratadistas que deixaram contribuiçốes preciosas para a compreensão fonológica da língua $\mathrm{cm}$ tempos passados, de modo particular para os lenômenos prosódicos que, como não têm letras para representá-los, nccessitam de uma descrição à parte, atenta c pormenorizada, por parte dos cstudiosos. Um desses autores é, scm dúvida, José Fícliciano de Castillo, em scu Tratado de Metrifícação Portugutesa, de 1850.

A divergência entre os estudiosos é outra fonte de pesquisa que pode revelar fatos importantes, como a ruptura de uma tradição com a adoção de novos parâmetros descritivos - porque a língua mudou c alguém notou. Castilho, por cxemplo, chamou a atenção para este fato, dizendo que não se deviam mais contar as sílabas átonas finciis dos versos - como. faziam os anligos e alguns de sua época. Said Ali, que também tem uma contribui-

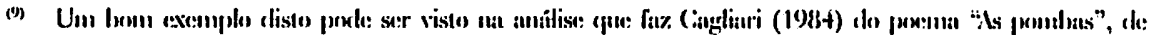

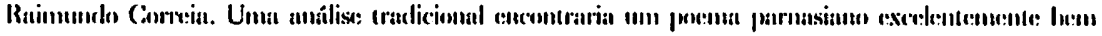

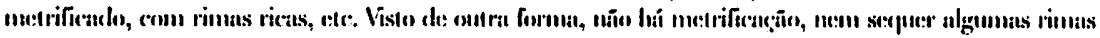

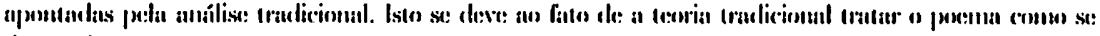

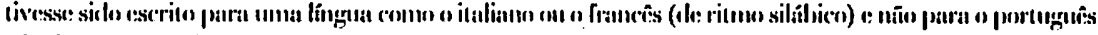

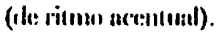

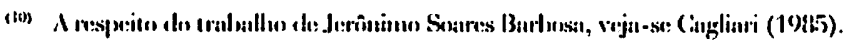




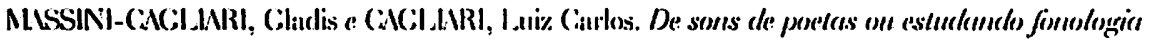
atrués da prossiot.

ção importante com sua Versificação Portuguesa, de 1948, voltou a discutir a questão, pois achava que os versos agudos acabam sempre em uma pau$s a$ - fato que foi questionado por Manuel Bandeira, que prefaciou seu livro. As razōcs alegadas por cles trazem contribuiçōes importantes para se entender melhor a cstrutura do verso c, conseqüientemente, os fatos prosódicos cm jogo.

Dado o fato de a pocsia metrificada usar padrões repetitivos de duração (sílabas, grupos de acento, grupos tonais, etc.), fica relativamente fácil descobril que tipo de padrão duracional a poesia emprega em carla verso c, a partir daí, lcvar adiante estuclos detalhados sobre o ritmo c as regras de atribuição de acento, mesmo $\mathrm{cm}$ sc tratando de textos antigos, para os quais não se tem registro falado. Um excmplo de estudo dessa natureza pode ser visto na tese de doutorado de Massini-Cágliauri (1995), em que a autora mostra como, no Português Medicval, alguns poctass contavam a última sílaba átona dos versos graves c outros não, fato que lhe: permitiu fazer hipóteses sólidas a respeito da atribuição de acento no Português daquela época.

Para se chegar aos padrões repetitivos de duração em versos de uma língua como o latim, isto é, para se chegar a um processo de escanclir corretamente versos latinos, cra preciso ter uma direção (da esquerda para a dircita) c ficar atento às cesuras c à concatenação das palaviàs. Um metro (dátilo, iambo, troqueu, anapesto, etc.) podia se estender sobre duats ou atć mais palavras (cm alguns casos de metros muito longos), mas não podia haver pausa entre scus componentes básicos. Pausa podia ocorrer apenas nas frontciras dos metros, caso contrário, o padrão rítmico esperädo scria quebrado. Obviamente, isto não significa, por outro lado, que se podia inscrir uma pausa nas frontciras de todos os metros de um verso. Para uma língua como o Portuguĉs, cstas restrições aplicam-se às junturass silábicas, gerando as regras de sândi.

A pocsia metrificada é rica cm material para estudo do fenômeno de: sândi, justamente pelo fato de nossos poctas acharem que precisavam là- 
zer versos isossilábicos. Diante dessa cxigência, os teóricos da literatura c gramáticos formularam regras que os ajudavam a definir o isossilabismo dos versos. Visto de outro lado, os poetas esforçavam-se por seguir essas regras. Como cm outros assuntos semclhantes, não faltam as cxceções, "distrações" " "licenças poćticas". No Português Medicval, cra costume assinalar os casos de sândi com clisōes claramente marcadas (através dáa junção, na cscrita, de mais de uma palavra e da queda de vogais). Vejamse, a cste respeito, os cxemplos (11) a (13). Depois, a cscrita ficou menos transparente, exigindo um trabalho especílico de interpretação $\mathrm{cm}$ função de um determinado isossilabismo esperado.

(11) Ay cu, cativ' e coytado, en forte pont' cu fuy narlo! Que scrui sempr' cndõado ond' um bem nunca prendi. En fortc pont' cu fuy nado, senhor; por uós c por mi!"!

(12) Por que uos ci cu, mha senhor; a dizer nada do meu mal? pois d'esto sõ|ol saberlor; scgurament', u nõ iaz al, que non m'aucdes a crecr; macar me uciades morrer? '?

(13) Rogaria cu mha senhor por Deus que mj l'czesse ben,

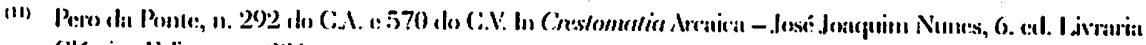
(Clissica lislitoria: p. 20:36.

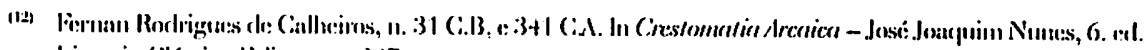

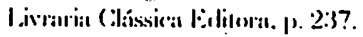




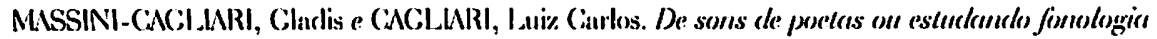
altrutés cha poesia.

mais ci d'cla tan gram pauor

que the non ouso falar ren,

con medode sc m'assanhar

c mj non querer pois falar:

Diria-lh'cu de coraçon

como me faz perder o sem

o scu bom parccer, mais non

ous' c tod' aquest' a mi) aucn

com medo de se mi assanhar

c mj non querer pois falar. ${ }^{1: 3}$

À scmelhança do metro, o fenômeno de sândi revela a não ocorrência de pausa ou de ccsura; além disso, mostra, de mancira apropriada, que houve queda de vogal ou ditongação. No Português do Brasil, é mais comum ocorrer ditongação $\mathrm{cm}$ juntura intervocabular quando se cncontram vogaiis com qualidades diferentes; poiém, no Português Europeu, o truncamento da primcira vogal ć mais comum, exceto quando a primeira vogal é átona c a scgunda é tônica, caso $\mathrm{cm}$ que ocorre a queda da primcira vogal.

Nos estudos dessc fenômeno na pocsia, um fato interessante a ser investigado é a determinação de quais os contextos possíveis que, de fato, acabam gerando casos reais de sândi. Alguns tcóricos acham que torlos os casos possívcis de sândi deveriam obrigar o pocta a formar um ditongo ou cxigir a supressão de uma das vogais ou a crase de vogais iguais. Na prática, o que se cncontra é um uso conveniente do fenômeno para cyustar o isossilabismo. Por cxcmplo, por que um pocta medicval como Airas Corpancho - cxemplo (14) - representa o sândi cm lh'ei, com'eu, led'andar;

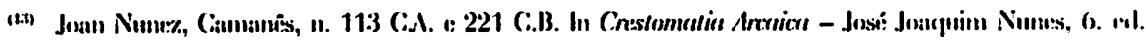
Livrouria (Clíssiea lialitor:a, p. 2+1). 
Lh'estaria, mas não em Pero ei, quando a, Lh'ei a? Qual ć o contexto exigentc ou mais favorável? Scqüîncias de ditongos (cf. ei eu) não permitiam a ocorrência de nenhuma forma de sândi? lisstas questōes exigem ainda cstudos cspecíficos.

(14) Pero ci gran sabor de lhe falar; quando a ucjo, por lhe nõ pesar; nô lh'ci a dizcr ren de com'cu podcria Icd'andar c lh'cstaria bem. ${ }^{1+}$

\section{POESIA E DIACRONIA}

Como se afirmou na Introdução destc artigo, $\mathrm{cm}$ alguns casos, a consideração da pocsia como objeto de cstudo pode favorccer a descrição de alguns fenômenos fonológicos (como, por cxcmplo, a cstruturação silálica de uma língua). Ėm outros casos, porćm, torna-se obrigatória, pois não só a consideração de textos poćticos favorece, mas viabiliza, no scntido estrito da palavra, a descrição de fenômenos (os prosódicos, por exemplo - como acentuação c ritmo) que scriam insondáveis atravćs de textos cscritos cm prosa. Em relação a fases passadas da língua, $\mathrm{cm}$ que não havia tecnologia suficiente para "gravar" a fala, cste ć um fato de cxtrema relevância, uma vez que não existe outra mancira de perscrutar fenômenos dessc tipo.

Para exemplificar csta possibilidade de se estudar fenômenos prosódicos de um tempo passado da língua através da pocsia, scrão considerados alguns fatos do Português Arcaico (doravante, PA), cstudados através das cantigas de amigo contidas no Cancioneiro da Biblioteca Nacional de lisboa (de agora em diante, CBN).

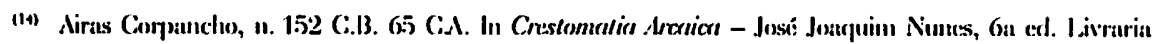
Clissica Hilitorn, p. 229.
} 


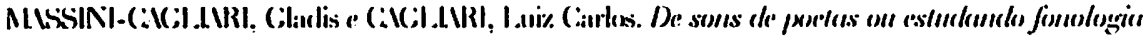
alrurusis cke poessiot.

Para se chegar ao valor dos parânetros do acento em PA, deve-se estudar mais detidamente as palavras e sua estrutura métrica. Para tal, é possível recorrer a uma metodologia análoga à de I lalle \&. Keyser (1971), que esturlaram a cvolução da acentuação do inglês attavés de textos poéticos, comespon-

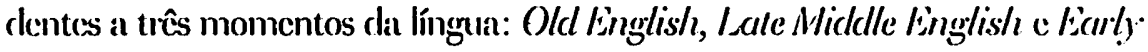
Mockem linglish. Apenas para a última fase da sua análise, dispunham de: dicionários de rimas e observaçôes de tratadistas solore a posição do acento nats palavras da ćpoca; para as outras deas lases, tiveram que; procurar; nos limitess dos próprios versos, dispositivos que indicassem qual (ou quais) palavial(s) possuía(m) o(s) acento(s) principal(is) do verso. ${ }^{1.5}$ L im relagão aos poemats da primcira fase: (O/d linglis/l), as palavmas foram focalizarlas de acorrlo com an scguinte estratégia - I latle \&. Keyser (1971: 87):

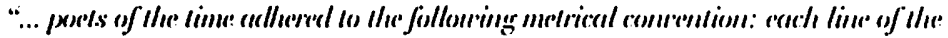

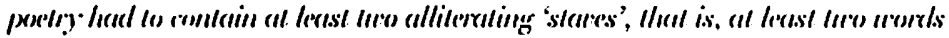

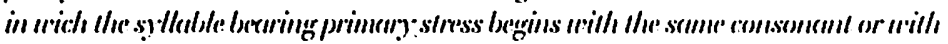

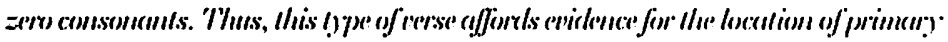

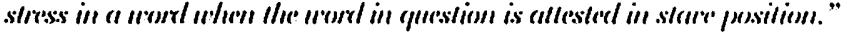

Já para o secgundo período, I lalle S. Keyser escollheram os pocmats de: ('haucer; cuja estrutura ("icmbic pentameter") fornece eviclencials dat localizaisäo dos acentos nos versos (e, consecpüentemente, no interior das palavrass).

Assim como cm l lalle \& Keyser (1971), liar-se necessírio arlotal uma estratégial, a partir da própria estrutura dos versos, que aponte qual palavea recebe o acento principal. lim muitos dos versos, apenas a última palavra (ou a sílaba proeminente da última palavra) recebe o acento, isto é, constitui o úmico acento do verso. Lm outros, várias palavaras recehem acento. No entanto, o último acento do verso é sempre mais forte do (que: os outros. Isto tudo pode ser observado a partir rlos cexemplos em (1.5): ${ }^{11}$

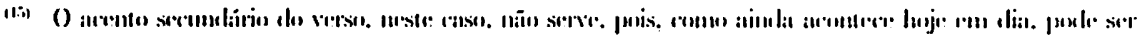

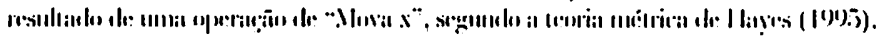

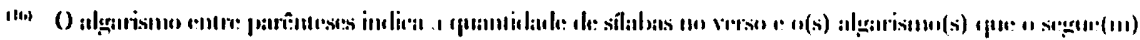

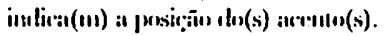


(15) Cantiga 495 (CiBN 1282): :?

Quantas sabedes amar amigo treydes comig'a lo mar de Vigo:

E Banhar-nos-cmos nas ondas!
(9) 4-9

(9) $4-9$

(8) $5-8$

Cantiga 16 (CIBN 565): :":
Bon dia vi amigo,
(6) $4-6$
pois seu mandad'ei migo,
(6) $4-6$
louģana.
(2) 2

Portanto, a estratégia acpui ardotarla consiste em focalizar as palatvaas que aparecem no lim de carla verso, pois sĩo, com certeza, portadoras do acento principal do verso (ou, em outros termos, de uma proemincencia nos níveis superiores ao do pé). De posse da informação de cue estas pala-

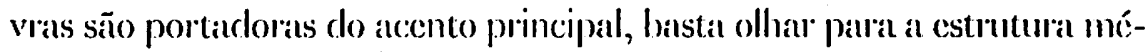
trica do poema, pois cla fornece, através da observaçiono da quantidade de sílabas poćticas por verso e da cstratégia de versificação do trovador (contar ou não as átonas linais), a posição da tônica.

A partir dessas premissas, Massini-Cagliani (1995) desenvolveu um esturlo a respecito do percurso histórico da acentuação do lation ao Portuguĉs Brasileiro attual, passando peto PA, que chegou às seguintes conclusōes:

- a grande maioria das palavias do corpus é paroxítona - o que vem a confirmar a hipótese, levantada anteriormente em Massini-Cagliani (1995: 181-203), com base em inlormacyócs a respeito dos procedimentos de metrificação dos trovarlores medievais galecgo-portugueses (às ve-

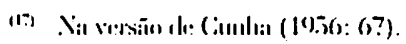

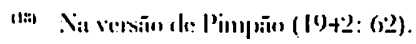




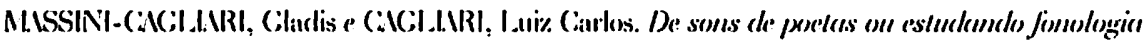
crircurés cla poessirs.

zce considerar as sílabas átonas de final de verso como integrantes do verso, às vezes, não considerá-las), do troqueu moraico como pé básico único do PA, já que a pauta paroxítona ć o padião trocaico canônico.

- o PA é sensível à quantidade silábica na construção dos pés. lím outros termos, o que isto quer dizer é que qualquer sílaba longa (ou pesarla) posicionada na penúltima ou última posição silábica da palavıa atrai o acento principal. É o que pode ser visto nos exemplos abaixo:

$$
\text { (16) }
$$

\section{a. sagrádo} $\cup \cup \cup$

b. uírgo $-\cup$ vs.

vs. sagraçón

$\cup \cup-$

uiigứu

O cxcmplo (16b) mostra também que, quando as duas últimas sílabas da palavia são longas, é a última que recebe o acento. Além disso, os cxemplos cm (16) provam que, $\mathrm{cm}$ relação à escolha do valor do parâmetıo que rege que sílabas são consideradas leves ou pesadas, o PA escollheu contar os clementos da rima como um todo c não só do núcleo - como demonstrado cm (17).

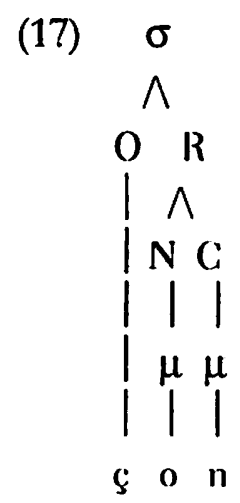

sagraçon

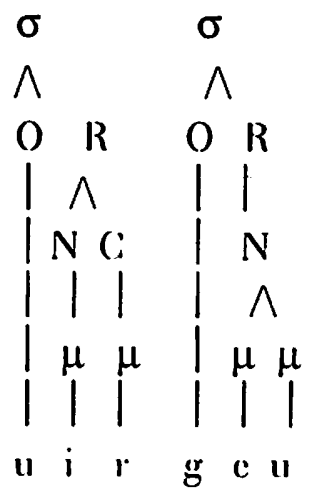

uingeu 


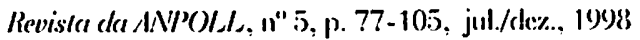

Além do acento, outros fenômenos fonológicos do PA podem ser "recuperados", isto é, descritos, a partir da métrica das cantigas de amigo. Por excmplo, considerando-se a divisão que os trovadores fazem dos versos cm sílabas poćticas, a cxemplo do que fez Cunha $(1961,1982)$, podese dizer se se está diante de um ditongo ou um hiato, ao considerar um cncontro vocálico.

Por exemplo, em (18), que contém uma estrofe da cantiga CiBN 563, de D. Dinis, na versão de Nunes (1973: vol. Il: 14), pode-se saber; a partir da contagem das sílabas poćticas, que em sei (linha 2), se cstí diante de ditongo, ao passo que $\mathrm{cm}$ sõo (linha 4) e queria (linha 5), de hiato: ${ }^{19}$

\begin{tabular}{|c|}
\hline Fe/zc/-o/ por/ cn/co/bcr/ta, \\
\hline $\mathrm{cal} / \mathrm{sci} / \mathrm{que} / \mathrm{se} / \mathrm{fo} / \mathrm{ma} / \mathrm{ma} / \mathrm{tar} /$ \\
\hline an/te/ que/ a/ mi/ fa/zcr/ pc/sali/ \\
\hline $\mathrm{c} / \mathrm{por} / \mathrm{cs} / \mathrm{to} / \mathrm{sö} / \mathrm{o} / \mathrm{ccr} / \mathrm{ta}$ \\
\hline que/ an/t'cl/ que/ri/a/ $/ \mathrm{mo} / \mathrm{rrcr}^{\prime} /$ \\
\hline $\mathrm{ca} / \mathrm{mi} / \mathrm{sol} / \mathrm{cun} / \mathrm{pe} / \mathrm{sar} / \mathrm{ra} / \mathrm{zcr} /$ \\
\hline
\end{tabular}

Úm caso digno de discussão é a ocorrência da palavra "liria", na centiga CiBN 1173, de Juião Bolsciro, a respcito da qual pairam dúvidas quanto à localização do acento (na antepenúltima ou na penúltima sílaba?), porque, além de não ocorrer em posição final de verso, não se sabe ao certo sc o encontro vocálico u forma um ditongo ou um hiato. Nunes (1973,

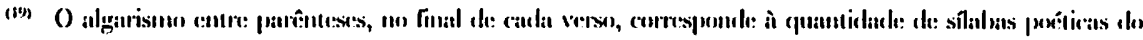

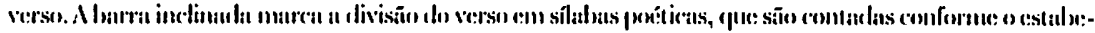

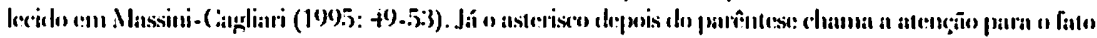

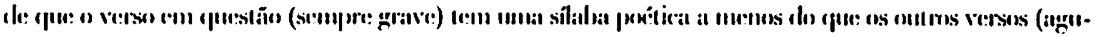

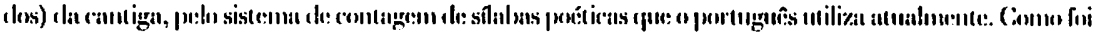

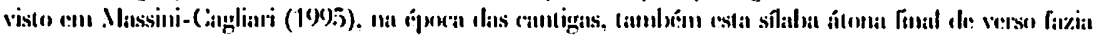

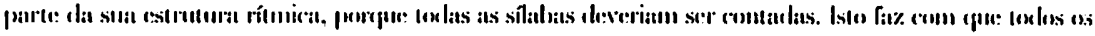

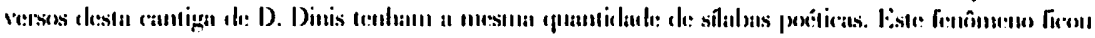

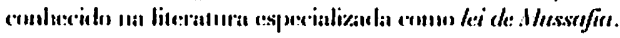




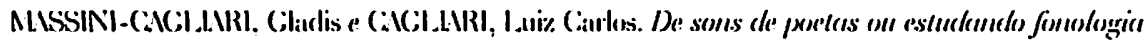
alurwis ele peresion.

vol. II: 364-365) considera-a paroxítona, já que grala "liria" (no seu padrão ortográfico, a forma proparoxítona scria "lírias") - c , portanto, possuidora de um hiato ı. O interessante é que a estrutura poética da cantiga em que ocorre esta palavra, felizmente, pode fornecer pistas a respeito dessas dúvidas, mesno estando cla em posição medial, porque, na maioria dos versos, octossílabos agudos, os acentos aparcecem nas $5^{\text {¿ }}$ e $8^{\text {¿ }}$ sílabas como cxcmplificarlo $\mathrm{cm}(19)$ :

(19)

ora meu amigo por mi,

que nunca melhor leita vi,

mais, como x'ć mui trobador;

fez ũas lirias no son

que mi sacam o colaçon,

Muito ben se soube buscar;

por mi ali quando a fez,

en loar-me muit'c meu prez

mais de pran, por xe mi matar;

fez ũas lirias no son

que mi sacam o coraçon,

Per bõa lé ben baratou

de a por mi bōa fazer

c muito lho sei gradecer;

mais vedes de que me matou,

f $\%$ ũas lirias no son

que mi sacam o coraçon,
(8) 5-8

(8) 5-8

(8) $5-8$

(8) 5-8

(8) 5-8

(8) $3-8$

(8) 5-8

(8) $4 / 5-8$

(8) $5-8$

(8) $3-8$

(8) 5-8

(8) $3-8$

(8) $+1 / 5-8$

(8) $5-8$

(8) 5-8

(8) 5-8

(8) $5-8$

(8) $3-8$ 
Desta mancira, "lirias" deve ser considerada paroxítona, encaixando-se no padrão canônico do PA, c A, um hiato.

Além disso, a consideração de fenômenos de metrificação no PA podem ser muito útcis na discussão do status dos clíticos: palavras ou não? No excmplo (20), retirado da cantiga CBN 1119, de Pero de Berdia, o artigo o aparece $\mathrm{cm}$ uma posição privilegiada (final de verso), que nos permite determinar sc recebe ou não o acento principal (do verso). Observando o padrão de rimas da cantiga cm questão, pode-sc notar que ant'o rima com tanto - o que indica que, neste caso, o artigo não recebe o acento principal do verso $\mathrm{e}$ que, portanto, por não ter uma independência prosódica, não deve ser considerado uma palavra fonológica.

(20) Na versão de Nunes (1973, vol. II: 319):

Sc m'cl descjasse tanto

como dizia, logo ant'o

tempo que disse verria,

mais sci que non me queria

tam gram ben como dizia.

Na versão do CBN:

Se mel desciasse tanto

Como dizia logo anto

Tempo q̃ disse viria

Mays sey ã me nõ q̃ria

Tã grã bẽ como dizia

Tais conclusõcs, importantíssimas para a descrição do componentc fonológico do PA, considcrado na sua completude, jamais poderiam ser 


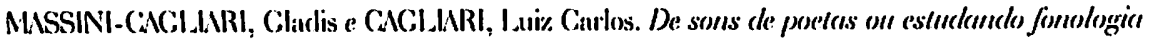
atraviés cla poessia.

alcançadas, sem que fossem tomados textos poéticos como basc para a formação de um corpus.

\section{CONCLUSĀO}

Os exemplos apresentados c discutidos anteriormente provam que, mais do que ser considerada apenas cm uma Cramática lato senstı, como o faz Mattoso Câmara (1953), a pocsia ć uma forma çue tem por basce o sistema da língua, como todas as outras, cmbora possa ser considerada de uso especializado (cf. Allen, 1973). Portanto, deve ser considerada como uma fontc lcgítima de dados para o cstudo da língua $\mathrm{cm}$ que foi cscrita. Além disso, cm relação a alguns fenômenos fonológicos (os prosódicos, por exemplo), como foi visto no item 1 deste traballıo, deve ser considerada como uma fonte privilegiada. No entanto, cm rclação ao estudo desses mesmos fenômenos $\mathrm{cm}$ um momento passado da língua, a considcraçĩo de textos poéticos é o fator que possibilita a descrição do componente prosódico da língua, scm o que scria impossível perscrutar essa nuance dos sons do nosso passado.

ABSTRICT: This paper aims to demonstrule how gramalical descripliom can be fanoured by the inclusion of postry in phomological studies, particularly in prosedic phenomena resecerch. As far as a diachuronic approsech is concerned, Ihe wilizalions of a poetical corpus and metric treratise are the only possible arey to acquire a retsomable description of the prosodic system of a langucagr, in anciont times.

Kl:HTHORDS: poetry; melrification; phomologn; prosisly:

\section{BIBLIOGRAFIA}

ABI:RCRROMBIL, D. (1965) Studies in Phonelics and Iinguistics. I ondon, Oxford Univensity Presis. (1967) Elements of Generd I'homelics. Edlinburgh, Eclinhurgh Univisity Press. 
Revista ck ANPOLL, " " 5, p. 77-105, jul./de\%., 1998

ALI, M. S. (1948) Versificuıçōo Porlugguêsa. Rio de Janciro, Imprensa Nacional.

ALLLEN, W. S. (197:3) Accent and R/y thm - Prosodic Features of Ialin and Creek, a stundy in theory. and reconstruction. Cannbridge, Cambridge Univesity Press.

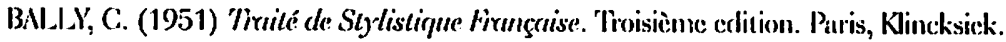

BARBOSI, J. S. (1822) Ciramatica Philosophica de Lingua Porluguesa. I,ishoa, Typographia da Acadenia das Sciencias.

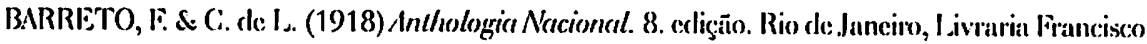
Nves.

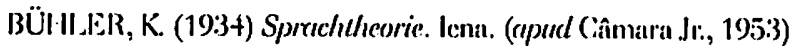

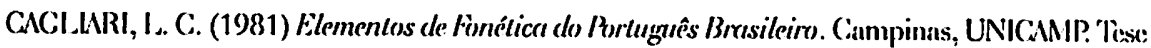
de Livor:-Docência defendida em 1982.

p. 67-96.

(1984) Análise fonćtica do ritmo em pocsia. KPH, n. 3. Campinas, IIL_ - UNICAMP,

(1985) O ritmo do português na interpretação de Jerônimo Soares Barbosa. Ancris do I

Encontro Nacionst de Fonćtica e Fonologica. Florianópolis, Universidade Federal cle Santa Catarina, p. 27-38.

(1989) Marcadores prosódicos na escrita. Esturedes Lingiaisticos XXIIII-Ancris de Seminírios do GEL. Lorena, p. 195-203.

(1992) Prosódia: algumas fungōes dos supra-segmentos. Crudernos de Lstudes / ingüis-

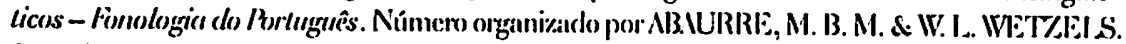
Cimpinas, UNICUMP, IEL, DI, p.137-151.

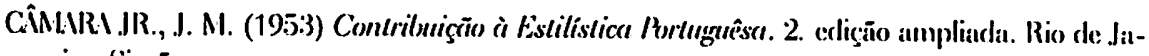
neiro, Simōes.

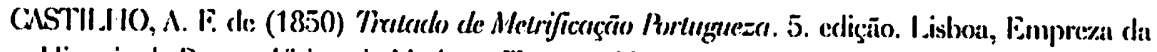
I listoria de: Portugal/L ivraria Morkerna Tỵpographia, 1908.

CAVAICANTI PROENGa, M. (1955) Rilmo e Roesia, Rio de Jancio, Ory. Simōes Editora, Coleção Rex (reimpresso).

CIIOMSKY, N. \& M. II. (1968) T\%e Sound Ratlern of Einglish. New York, Hauper \&. Row.

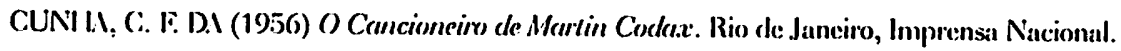

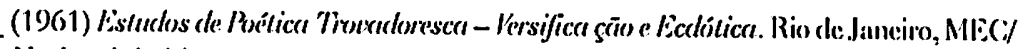
Instituto Nacional do l iviro.

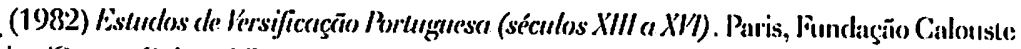
Ciullenkiaur/Centon Culcural Pontugutês.

CROOT, $A$. W. de (1968) Plonetics in its relation to acsthetics. In MAI MBBERC, B. (ed.) Manural of P'/onetics. Ansterdam, Nordlo-I lolland Publishing Co., p. 5:3:3-549. 


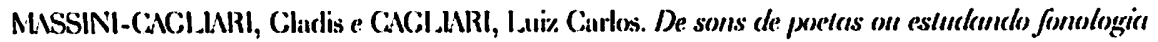
atrovés cla proessirt.

I LII.L.E, M. (1989) Addendum to Prince's "Metrical Porms". In KIPARSKY', P. \& C. YOUMINS

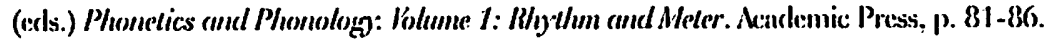

llarper \& Row.

S. S. J. K. (1971) English Stress: ils form, its grouth, and its mole in merse. New York:

I IN I. ID.NY, N. A. K. (1970) A Course in Spoken English: Intomation. I .omdon, Oxford University Press.

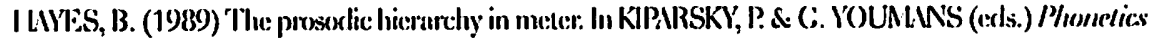

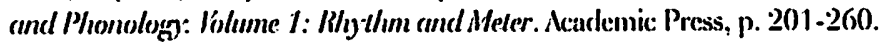
(199I) Metrical Stress Theory - Principles and Citse: Studlies. UC/LI (dlorefi).

Prrss. (1995) Metrical Stress Theory - Principhles and (iass Studies. Universily of Chicago

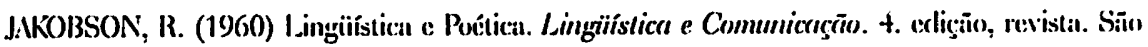
Paulo, Cullerix, 1970.

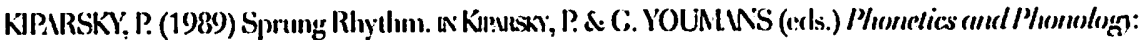

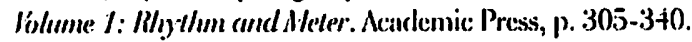

I.FIIISTE, I. (1985) Rhỵthm of Poxetry, Rhỵthm of Prost. In FROMIKIN, V. A. (org.) I/hmelic Linguistics - essti)s in homor of Peter lordefogred. Orlando, Anadeninic, p. 145-155.

(1900) Plsonetic investigation of metrical structure in orallỵ produced por:try. Jenurnal of Plometics. 18(2): 12:3-13:3.

M.N.INC; J. M. (197:3) The Theory of Clesssical Arrbic Metrics. Ph.D. Thesis. Departument of

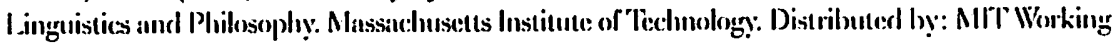
Paptrs in l inguistics.

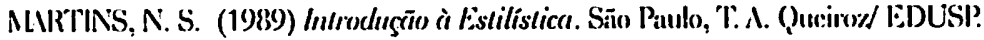

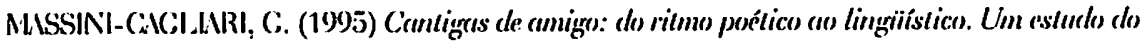

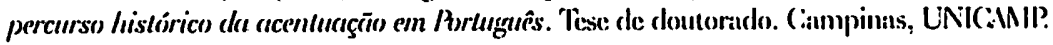

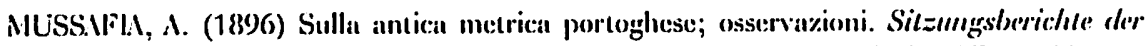
philossophish-hishorichen Classe der Käriserlichen Akedemic der Ilisstuschafien. Wien, 13:3.

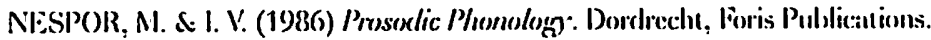

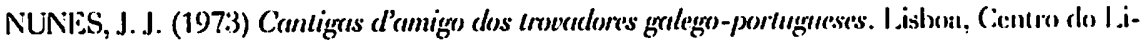
vor Brasileiro. 1. edliḡio: 19:26/19:29.

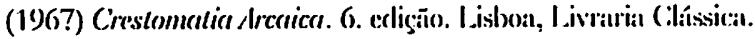

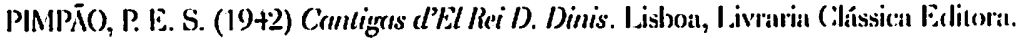

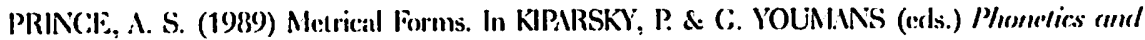

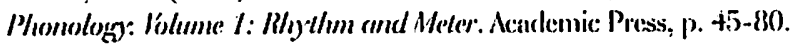

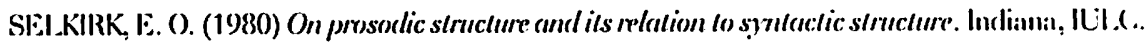




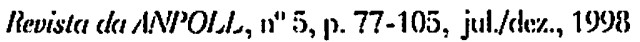

VERI,UYTIEN, S. P. M. (1982) Recherches sur la prosodie el la mélrique du tirmgrais. Willijk, Universitaire Instelling $A$ ntwerpen. (leste de Doutorado)

YOUNIANS, C. (1989) Introduction: Rhythm and Mcter: In KIPARSKY, I. \&. C. YOUNINS (ceds.) Phonetics and Phomologg; Holtme I: R/ythm and Heter. Acardemic: Press. p. 1-14.

Cancioneiro da Biblioteca Nacional (Colocci-Bramcati). Cocl. 10991. Rejprodugsão fact-similadal. I.jishon, Biblioteca Nacional/Imprensa Nacional - Cissil da Nocela, 1982. 